\title{
Risk Conception and Evaluation in Taiwan Financial Markets
}

\author{
Yin-Ching Jan \\ Department of Distribution Management \\ National Chin-Yi University of Technology \\ 57, Sec. 2, Chung-Shan Rd., Taiping Dist., Taichung City, Taiwan, R.O.C. \\ Tel: 886-4-23924505 E-mail:jan511@mail.ncut.edu.tw
}

Received: Nov. 12, 2014 Accepted: Dec. 22, $2014 \quad$ Published: June 1, 2015

doi:10.5296/ajfa.v7i1.6602 URL: http://dx.doi.org/10.5296/ajfa.v7i1.6602

\begin{abstract}
An experiment is designed to explore risk conception and evaluation of investors. A new risk measurement, which is called martingale variance, is included. The new measure uses previous return as benchmark instead of mean return to calculate variance. The results show that respondents are more care about expected loss than variance, but are indifferent between variance and loss probability. Meanwhile, the respondents prefer martingale semivariance to martingale variance significantly. The weighted martingale semivariance also dominates martingale semivariance. The results can be helpful to explain the relationship between risk and return.
\end{abstract}

Keywords: Downside risk, Martingale variance, Martingale semivariance 


\section{Introduction}

The foundation of an asset pricing model is assumption of risk evaluation. When the assumption doesn't conform to the risk conception and evaluation of investors, the asset pricing model wouldn't explain the relationship between expected return and risk. The accuracy of Capital Asset Pricing Model (CAPM) would reside in whether investors apply beta to evaluate investing risk. The debate of CAPM in explaining risk/return focuses on the debate of the application of beta. Therefore, to expect an asset's return, we need to explore how investors evaluate risk in investing assets.

In this paper, an experiment is designed to examine risk conception and evaluation of investors in Taiwan Financial Markets. Experimentation is an important means in studying the risk perception, risk attitude, and risk/return relationship. For example, Gneezy and Potters (1997) showed that the more frequently returns on investment are evaluated, the more risk averse investors will be. Levy (1997) designed experiments to test CAPM, and showed partial support of the CAPM. Olsen (1997a, 1997b) found that the risks perceived by professional portfolio managers were multidimensional, and the most important factor is return below target. Wood and Zaichkowsky (2004) applied segmentation approach to identify segments of individual investors based on investing attitudes and behaviors. Siebenmorgen and Weber (2004) examined the effect of different investment horizons on investors risk behavior. Veld and Veld-Merkoulova (2008) found that most investors implicitly use more than one risk measure. For those investors who systematically perceive risk according to the same risk measure, semivariance of returns is most popular. In effect, the breakthrough results of behavior economy come from the experiment study of Kahneman and Tverskey (1979) and Tverskey and Kahneman (1981).

The results show that respondents are more care about expected loss than variance, but are indifferent between variance and loss probability. When autocorrelation of time series return is taken into account, the respondents prefer martingale semivariance to martingale variance significantly. Meanwhile, weighted martingale semivariance also dominates martingale semivariance. The results are contrary to the assumption of risk evaluation of existing asset pricing model, leading the failure of explanation of risk/return relationship.

The remainder of the article is organized as follows. Next Section presents the experiment and methodology. Section 3 shows the experimental results. Finally, Section 4 has concluding remarks.

\section{Methodology}

A questionnaire is designed to explore the risk conception and evaluation of investors. There are three parts in the questionnaire. The first part explores what kind of risk investors care about. The second investigates whether the investors will concern risk involved autocorrelation of time series return. The last wants to know some characteristics of respondents.

The first part modifies the work of Veld and Veld-Merkoulova (2008). Their work designs two assets with four risk measures, which include variance, semivariance, probability of loss, 
and expected value of loss. One asset has a lower risk measure compared to another asset, but has three higher risk measures than the other. When a respondent choose the asset with a lower risk measure, then we can ascertain what kind of risk the investor care about. Nevertheless, their designed questions would be complex for investors. Therefore, we modify their design to two assets with two risk measures. Each asset has a lower risk measure and a higher risk measure compared to another asset. There are four questions in the first part. The first question is designed to identify respondent's risk attitude. The traditional question let respondent to choose one among three options: risk-averse, risk-love, or risk-neutral. We let the respondent to have seven options. The first question is as follows:

Q1. Suppose that you plan to invest New Taiwan Dollar (NT\$) 100,000 of your own money. You can choose between two financial products. Both products will be liquidated after one year, and the expected payoffs are NT\$105,000 (there is rate of return of 5\%). What do you choose?

A: $100 \%$ chance of NT $\$ 105,000$ payoff.

B: $50 \%$ chance of NT\$55,000 payoff, and 50\% chance of NT\$155,000 payoff.

Choose A

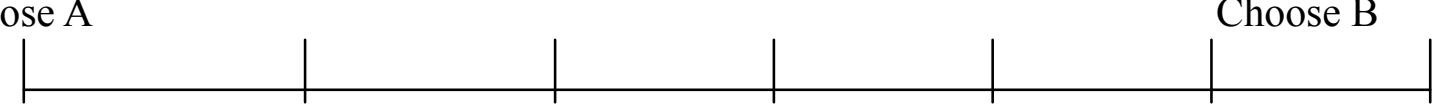

Absolutely Always Sometime Indifference Sometime Always Absolutely

A $100 \%$ risk-averter will absolutely choose asset A, while $100 \%$ risk-taker will absolutely choose asset B. The risk-neutral will be indifferent between these two assets. The second question is designed to explore the respondent's concern about symmetric risk, which is measured by standard deviation, or downside risk, which is measured by semi standard deviation.

Q2. Suppose that you plan to invest NT\$100,000 of your own money. You can choose between two financial products. Both products will be liquidated after one year, and the expected payoffs are NT\$105,000 (there is a rate of return of 5\%). What do you choose?

C: $25 \%$ chance of NT\$75,000 payoff, and 75\% chance of NT\$115,000 payoff. (The asset C has standard deviation of $\$ 17,321$ and semi standard deviation of $\$ 15,000$ )

D: $10 \%$ chance of NT $\$ 70,000$ payoff, and $87.5 \%$ chance of NT $\$ 105,000$ payoff, and $2.5 \%$ chance of NT $\$ 245,000$ payoff. (The asset D has standard deviation of $\$ 24,749$ and semi standard deviation of $\$ 11,068)$.

We design third question to reflect respondent's risk attitude between system risk and expected value of loss, and fourth question to reflect respondent's risk attitude between system risk and probability of loss.

Q3. Suppose that you plan to invest NT\$100,000 of your own money. You can choose between two financial products. Both products will be liquidated after one year, and the 
expected payoffs are NT\$110,000 (there is a rate of return of $10 \%$ ). What do you choose?

E: $15 \%$ chance of NT $\$ 80,000$ payoff, $40 \%$ chance of NT $\$ 92,000$ payoff, and $45 \%$ chance of NT $\$ 136,000$ payoff. (The asset E has standard deviation of $\$ 23,900$ and expected loss of $\$ 62,000)$.

F: $10 \%$ chance of NT $\$ 64,000$ payoff, $60 \%$ chance of NT $\$ 99,000$ payoff, and $30 \%$ chance of NT $\$ 147,000$ payoff. (The asset E has standard deviation of $\$ 26,400$ and expected loss of $\$ 42,000)$.

Q4. Suppose that you plan to invest NT\$100,000 of your own money. You can choose between two financial products. Both products will be liquidated after one year, and the expected payoffs are NT\$110,000 (there is a rate of return of 10\%). What do you choose?

G: $45 \%$ chance of NT\$92,000 payoff, and $60 \%$ chance of NT\$122,200 payoff. (The asset G has standard deviation of $\$ 14,700$ and probability of loss of $40 \%$ ).

H: $10 \%$ chance of NT $\$ 20,000$ payoff, and $90 \%$ chance of NT\$120,000 payoff. (The asset H has standard deviation of $\$ 30,000$ and probability of loss of $10 \%$ ).

\section{New risk measure and evaluation of investors}

The calculations of variance and semivariance don't take autocorrelation of time series return into account. Goyal and Santa-Clara (2003) include the autocorrelation feature in their risk measure. Jan and Wang (2012) use of martingale variance (MVAR) to measure risk. The martingale variance uses previous return as benchmark, instead of average return, to compute variance. Specifically, it is calculated as follows:

$$
\begin{aligned}
\operatorname{MVAR}(R) & =\frac{\sum_{t=1}^{T}\left(R_{t}-R_{t-1}\right)^{2}}{T} \\
& =\frac{2\left\{\left(\sum_{\mathrm{t}=1}^{\mathrm{T}} \mathrm{R}_{\mathrm{t}}^{2}-E(R)^{2}\right)-\left(\sum_{t=1}^{T} R_{t} R_{t-1}-E(R)^{2}\right)\right\}}{T} \\
& =2\left\{\operatorname{VAR}(R)-\operatorname{COV}\left(R_{t}, R_{t-1}\right)\right\}
\end{aligned}
$$

The second part of the questionnaire is designed to detect whether the investors will concern risk involved autocorrelation of time series return. I use diagram instead of numeric rate of return to reflect the time series pattern. There are three questions in this part. The first question, which is shown below, is designed to compare the traditional variance and martingale variance. We still use the Likert seven point scales.

Q1. The following diagrams show two time-series pattern of asset's return, whose average returns equal to zero. Which asset do you think more risky? 

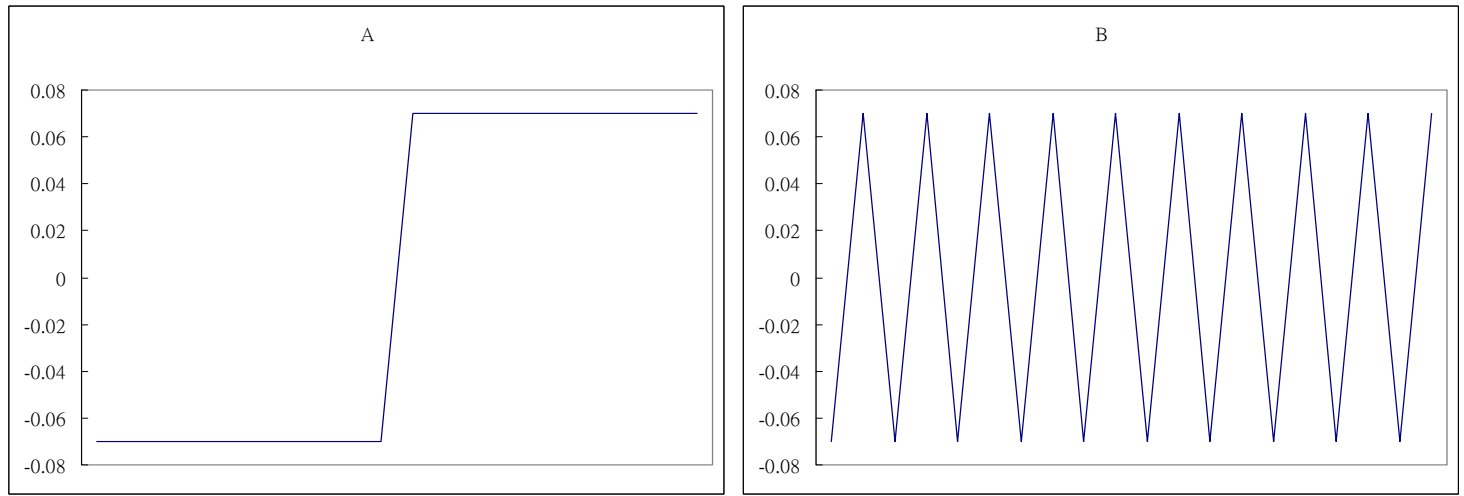

Choose A

Choose B

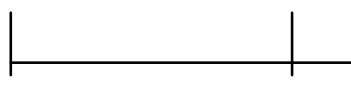

Absolutely

Always

Sometime

Indifference

Sometime Always

Absolutely

We see that the variance and semivariance of $\mathrm{A}$ and $\mathrm{B}$ are same. However, the martingale variance of asset $B$ is higher than that of asset $A$. That is because the autocorrelation feature has been included in the calculation of martingale variance.

The second question lets the respondent to choose either martingale variance or martingale semivariance. The martingale semivariance (MSVAR) is similar to the relative semivariance. Nevertheless, the martingale semivariance, which is shown as below, applies past return as the time-varying return benchmark.

$$
\operatorname{MSVAR}(R)=\frac{\sum_{t=1}^{T}\left\{\operatorname{Min}\left(0, R_{t}-R_{t-1}\right)\right\}^{2}}{T}
$$

Q2. The following diagrams show two time-series pattern of asset's return, whose average returns equal to zero. Which asset do you think more risky?
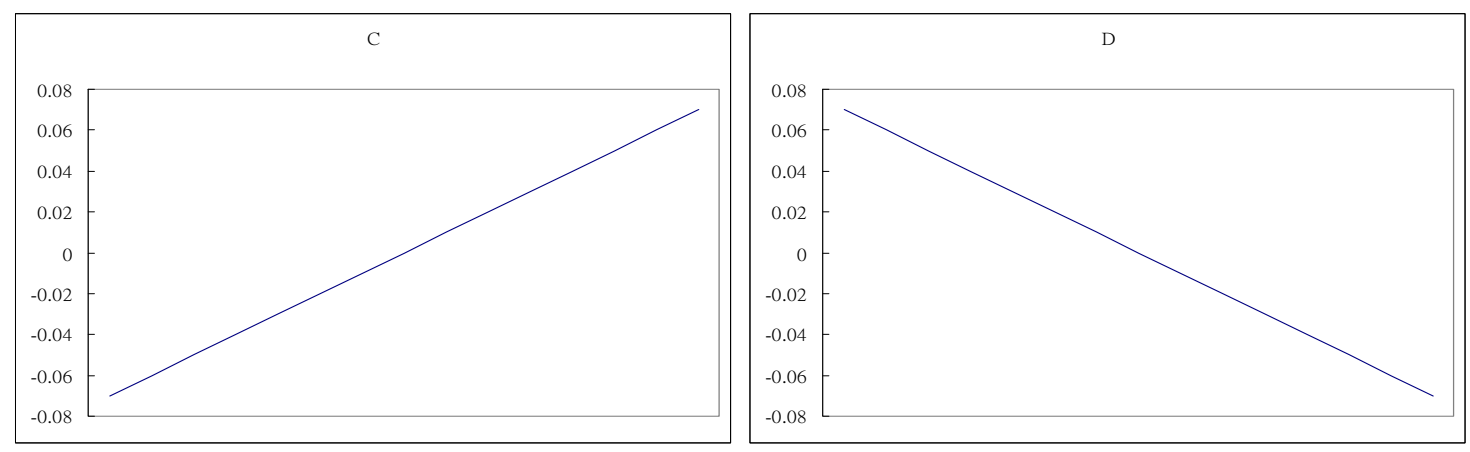

The time series return of asset $\mathrm{C}$ is growing, while asset $\mathrm{D}$ is downward. However, the variance, semivariance, and martingale variance of $\mathrm{C}$ are the same as those of $\mathrm{D}$. Nevertheless, the martingale semivariance of $\mathrm{D}$ is larger than that of $\mathrm{C}$. 


\section{I Macrothink}

Asian Journal of Finance \& Accounting

ISSN 1946-052X

2015, Vol. 7, No. 1

The martingale semivariance can't distinguish between the assets whose return rising firstly and then declining, and the assets whose return declining firstly and then rising. However, the investors may not be indifference between these two time series return pattern. We design third question as follows.

Q3. The following diagrams show two time-series pattern of asset's return, whose average returns equal to zero. Which asset do you think more risky?
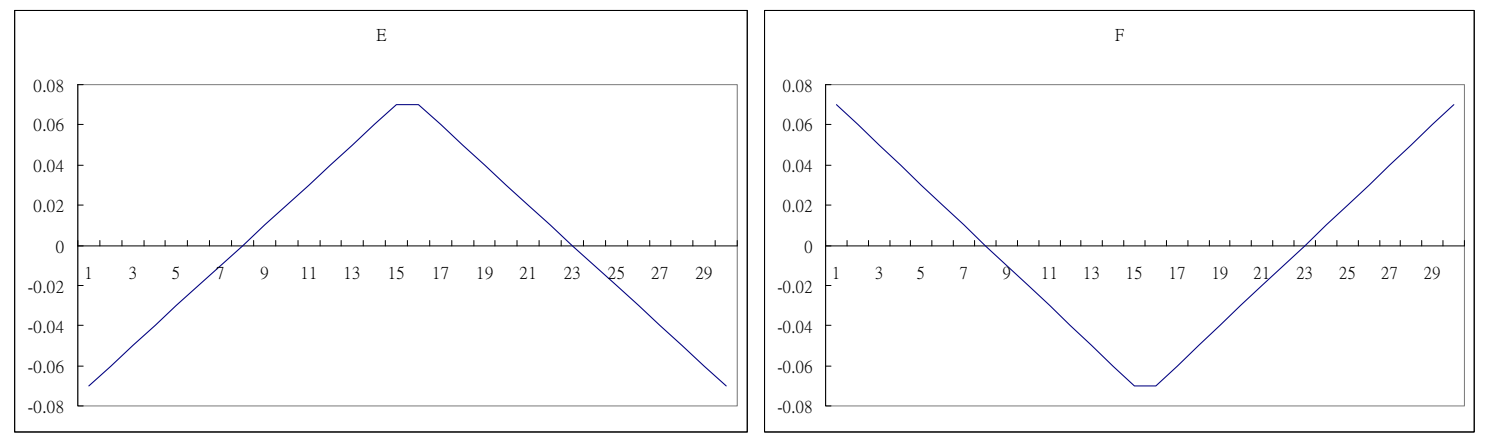

We can see that the assets $\mathrm{E}$ and $\mathrm{F}$ have the same measures of variance, semivariance, martingale variance, and martingale seimivariance. To separate these two return pattern by risk measure, Jan (2014) propose a weighted martingale semivariance (WMSVAR), which is reached by the combination of the martingale semivariance and the use of weighted average method. When we put more weights to the recent return variations, the weighted martingale semivariance of $\mathrm{E}$ would be larger than that of $\mathrm{F}$. That is,

$$
\operatorname{WMSVAR}(R)=\sum_{t=1}^{T} w_{t}\left\{\operatorname{Min}\left(0, R_{t}-R_{t-1}\right)\right\}^{2}
$$

The respondent's characteristics are put in the final part, including gender, whether diversified investing, and benchmark setting. We also design two questions to examine internal consistency in the last two questions. The questionnaire of the respondent's characteristics can be found in Appendix.

Gender differences in risk propensity and strategy in financial decision-making have been well studied. See Weber, Blais, and Betz (2002), and Fellner and Maciejovsky (2007) for example. Their results show that females are more risk-averse than males. We want to see whether the results also exist in Taiwan financial market.

To improve reliability of the study, we need respondents to be familiar with risk measurement. Therefore, the respondents are college students which major in finance. Specifically, all of the 191 respondents come from Department of Finance and Department of Finance and Insurance in National Taichung University of Science and Technology.

\section{Results}

Table 1 exhibits summary statistics for the respondents' characteristics. There are 120 respondents are female, which is $63 \%$ of the 191 samples. Most investors consider diversified portfolio when investing. Only $2 \%$ of the investors don't diversify. The most benchmark 
investor compared is market portfolio, which reaches $60 \%$. We employ Cronbach alpha to compute the internal consistency. Cronbach alpha is frequently used as a measurement to estimate reliability for multi-item scales. Cronbach's Alpha for the last two questions reaches 0.802 , which shows a reliable internal consistency.

Table 1. Summary statistics for the respondents' characteristics

\begin{tabular}{|l|c|c|c|}
\hline \multirow{2}{*}{ Respondent's characteristics } & Count & Frequency \\
\hline \multirow{4}{*}{ Gender } & Male & 70 & $36.8 \%$ \\
\cline { 2 - 4 } & Female & 120 & $63.2 \%$ \\
\cline { 2 - 4 } & Always consider & 41 & $21.6 \%$ \\
\cline { 2 - 4 } & Often consider & 87 & $45.8 \%$ \\
\cline { 2 - 4 } & Sometimes consider & 58 & $30.5 \%$ \\
\hline \multirow{3}{*}{ Benchmark } & Never consider & 4 & $2.1 \%$ \\
\cline { 2 - 4 } & Initial investment & 25 & $23.9 \%$ \\
\cline { 2 - 4 } & Risk-free rate & 111 & $60.3 \%$ \\
\cline { 2 - 4 } & Market portfolio & 4 & $2.2 \%$ \\
\hline
\end{tabular}

The summary statistics and t tests for paired risk measures are shown in Table 2. Remember that the measurement we used is Likert seven scales. A risk-neutral investor will be indifferent to these two assets, and will be measured by four. A risk-averse investor would be measured by less than four. The results show that the average of risk measure is 3.69 , and is less than 4 significantly, which implies that investors are risk-averse. The second figure shows the risk measured by variance versus semivariance. The mean, which is 3.68 , indicates that the respondents are more care about variance than semivariance on average, and reaches $5 \%$ significance level. It's surprised that the result doesn't conform to the evidences of Veld and Veld-Merkoulova (2008). They find that semivariance of returns is most popular for those investors who systematically perceive risk according to the same risk measure. The next two figures show that respondents are more care about expected loss than variance at $1 \%$ significance level, but are indifferent between variance and loss probability. The result is similar to the work of Veld and Veld-Merkoulova (2008) for bond investors, but is contrary to the work of Duxbury and Summers (2004), whose found that individuals' perceptions of risk are linked to loss probability. All the results show that the risk perception and evaluation of Taiwan investors isn't same as other financial markets. 
Table 2. Summary statistics and t tests for paired risk measures

\begin{tabular}{|l|c|c|c|l|}
\hline \multicolumn{1}{|c|}{ Risk attitude choice } & Mean & $\begin{array}{c}\text { Standard } \\
\text { Deviation }\end{array}$ & $\mathrm{t}\left(\mathbf{H}_{\mathbf{0}}: \boldsymbol{\mu}=\mathbf{4}\right)$ & P value \\
\hline Risk-averse versus Risk-love & 3.69 & 1.842 & -2.288 & $.023^{* *}$ \\
\hline Variance versus Semivariance & 3.68 & 1.903 & -2.238 & $.026^{* *}$ \\
\hline Variance versus Expected loss & 4.58 & 1.834 & 4.268 & $.000^{* * *}$ \\
\hline Variance versus Loss probability & 3.81 & 2.033 & -1.279 & .202 \\
\hline Variance versus Martingale variance & 4.21 & 1.881 & 1.525 & .129 \\
\hline Martingale Variance versus Martingale semivariance & 4.44 & 1.674 & 3.558 & $.000^{* * *}$ \\
\hline $\begin{array}{l}\text { Weighted martingale semivariance versus } \\
\text { Martingale semivariance }\end{array}$ & 3.80 & 1.447 & -1.849 & $.066^{*}$ \\
\hline
\end{tabular}

$*, * *, * * *$ denote $10 \%, 5 \%$, and $1 \%$ significance level, respectively.

The last three results examine whether the investors concern risk involved autocorrelation of time series return. When we compare variance in contrast to martingale variance, the respondents prefer martingale variance to variance on average, but don't reach significance level. The next figures present that the respondents prefer martingale semivariance to martingale variance at $1 \%$ significance level. Meanwhile, weighted martingale semivariance also dominates martingale semivariance at 10\% significance level. A high martingale semivariacne or weighted martingale semivariance implies that the asset's return is declining, leading a high loss probability and expected loss. Furthermore, there exists a liquidity risk when the asset's return is declining. Llorente, et. al (2002) found that the cross - sectional variation in the relation between volume and return autocorrelation is related.

The results may explain why most existing APM can't explain the risk/return relationship in the Taiwan Exchange Market. The low percentage in considering symmetric risk in Taiwan is same as other studies on the developing market, e.g., Veld and Veld-Merkoulova (2008). The results support downside risk studies of Stevenson (2001), Estrada (2003), and Ang, Chen, and Xing (2006), among others. The results can help to explain why the downside risk measures can result in improvement in risk/return relationship.

Table 3 shows the risk conceptions by respondent's gender. The results tells that male investors are more risk-seeking than female on average, but don't reach significance level. The results are not similar to the work of Weber, Blais, and Betz (2002), and Fellner and Maciejovsky (2007), who show that woman are more risk averse than man. The second result shows that male concerns semivariance, while female concerns variance. When compared variance versus expected loss, loss probability, and martingale variance, there is indifferent between female and male. The next result presents that male concerns about martingale semivariance in contrast to martingale variance as female, but is more cared about martingale semivariance than female at 5\% significance level. The last result in Table 3 tells that man concerns martingale semivariance, while woman concerns weighted martingale semivariance. 
The different reaches 5\% significance level.

Table 3. Two independent samples $t$ tests by gender

\begin{tabular}{|c|c|c|c|c|c|}
\hline Risk attitude choice & Gender & Mean & Standard & $\mathrm{t}$ & $\mathrm{P}$ value \\
\hline \multirow{2}{*}{ Risk averse versus Risk love } & Male & 3.94 & 1.828 & \multirow{2}{*}{1.409} & \multirow{2}{*}{0.161} \\
\hline & Female & 3.54 & 1.849 & & \\
\hline \multirow{2}{*}{ Variance versus Semivariance } & Male & 4.11 & 2.016 & \multirow{2}{*}{2.350} & \multirow{2}{*}{$.020 * *$} \\
\hline & Female & 3.42 & 1.799 & & \\
\hline \multirow{2}{*}{ Variance versus Expected loss } & Male & 4.45 & 1.985 & \multirow{2}{*}{-0.710} & \multirow{2}{*}{0.478} \\
\hline & Female & 4.65 & 1.750 & & \\
\hline \multirow{2}{*}{ Variance versus Loss probability } & Male & 3.85 & 2.234 & \multirow{2}{*}{0.159} & \multirow{2}{*}{0.874} \\
\hline & Female & 3.80 & 1.920 & & \\
\hline \multirow{2}{*}{ Variance versus Martingale variance } & Male & 3.99 & 1.943 & \multirow{2}{*}{-1.193} & \multirow{2}{*}{0.235} \\
\hline & Female & 4.33 & 1.840 & & \\
\hline \multirow{2}{*}{$\begin{array}{l}\text { Martingale variance versus } \\
\text { Martingale semivariance }\end{array}$} & Male & 4.79 & 1.775 & \multirow{2}{*}{2.213} & \multirow{2}{*}{$.028 * *$} \\
\hline & Female & 4.23 & 1.590 & & \\
\hline \multirow{2}{*}{$\begin{array}{l}\text { Weighted martingale semi variance } \\
\text { versus Martingale semivariance }\end{array}$} & Male & 4.10 & 1.499 & \multirow{2}{*}{2.185} & \multirow{2}{*}{$.030 * *$} \\
\hline & Femal & 3.62 & 1.391 & & \\
\hline
\end{tabular}

** denotes $5 \%$ significance level.

\section{Conclusions}

I design an experiment to examine risk conception and evaluation of investors. The results show that respondents are more care about expected loss than variance, but are indifferent between variance and loss probability. When autocorrelation of time series return is taken into account, the respondents prefer martingale semivariance to martingale variance significantly. Meanwhile, weighted martingale semivariance also dominates martingale semivariance. The results are contrary to the assumption of risk evaluation of asset pricing model, leading the failure of explanation of risk/return relationship.

I also explore the risk conceptions by respondent's gender. The results present that male concern about martingale semivariance in contrast to martingale variance as female. The results also tell that man concerns martingale semivariance, while woman concerns weighted martingale semivariance. All of the results can be applied to the calculation of risk and the examination of the return/risk relationship.

\section{References}

Ang, A., Chen J., \& Xing Y. (2006). Downside risk. Review of Financial Studies, 19, 1191-1239. http://dx.doi.org/10.1093/rfs/hhj035

Duxbury, D., \& Summers B. (2004). Financial risk perception Are individuals variance 
averse or loss averse? Economics Letters, 84, 21-28. http://dx.doi.org/10.1016/j.econlet.2003.12.006

Estrada, J. (2003). Mean-semivariance behavior: A note, Finance Letters, 1, 9-14.

Fellner, G., \& Maciejovsky B. (2007). Risk attitude and market behavior: Evidence from experimental asset markets. Journal of Economic Psychology, 28, 338-350 http://dx.doi.org/10.1016/j.joep.2007.01.006

Gneezy, U., \& Potters J. (1997). An experiment on risk taking and evaluation periods. Quarterly Journal of Economics, 112, 631-646. http://dx.doi.org/10.1162/003355397555217

Goyal, A., \& Santa-Clara P. (2003). Idiosyncratic risk matters! Journal of Finance, 58, 975-1008. http://dx.doi.org/10.1111/1540-6261.00555

Jan, Y. C. (2014). A Note on a New Weighted Idiosyncratic Risk Measure. International Journal of Financial Research, 5, 194-198. http://dx.doi.org/10.5430/ijfr.v5n3p194

Jan, Y. C., \& Wang J.M.C. (2012). A Note on Idiosyncratic Risk Measure. Journal of Money, Investment and Banking, 25, 119-123.

Kahneman, D., \& Tversky A. (1979). Prospect theory: An analysis of decision under risk, Econometrica, 47, 263-291. http://dx.doi.org/10.2307/1914185

Levy, H. (1997). Risk and return: An experimental analysis. International Economic Review, 38, 119-149. http://dx.doi.org/10.2307/2527411

Llorente, G., Michaely R., Saar G., \& Wang J. (2002). Dynamic Volume - Return Relation of Individual Stocks. Review of Financial Studies, 15, 1005-1047. http://dx.doi.org/10.1093/rfs/15.4.1005

Olsen, R. (1997a). Prospect theory as an explanation of risky choice by professional investors: Some evidence. Review of Financial Economics, 6, 225-232. http://dx.doi.org/10.1016/S1058-3300(97)90008-2

Olsen, R. (1997b). Investment risk: The experts' perspective. Financial Analysts Journal, 53, 62-66. http://dx.doi.org/10.2469/faj.v53.n2.2073

Siebenmorgen, N., \& Weber M. (2004). The influence of different investment horizons on risk behavior. Journal of Behavioral Finance, 5, 75-90. http://dx.doi.org/10.1207/s15427579jpfm0502_2

Stevenson, S. (2001). Emerging markets, downside risk and the asset allocation decision. Emerging Markets Review, 2, 50-66. http://dx.doi.org/10.1016/S1566-0141(00)00019-4

Tversky, A., \& Kahneman D. (1981). The framing of decisions and the psychology of choices. Science, 211, 453-458. http://dx.doi.org/10.1126/science.7455683

Veld, C., \& Veld-Merkoulova Y. (2008). The risk perceptions of individual investors, Journal of Economic Psychology, 29, 226-252. http://dx.doi.org/10.1016/j.joep.2007.07.001 


\section{Macrothink}

Asian Journal of Finance \& Accounting ISSN 1946-052X

Weber, E., Blais A., \& Betz N. (2002). A domain-specific risk-attitude scale: Measuring risk perceptions and risk behaviors. Journal of Behavioral Decision Making, 15, 263-290. http://dx.doi.org/10.1002/bdm.414

Wood, R., \& Zaichkowsky J. L. (2004). Attitudes and the trading behavior of stock market investors: A segmentation approach, Journal of Behavioral Finance, 5, 170-179. http://dx.doi.org/10.1207/s15427579jpfm0503_5 


\section{Macrothink}

\section{Appendix}

Questionnaire of the respondent's characteristics (in Chinese)

1. Your gender is: $\square \quad$ Male $\square$ Female.

2. When you invest a specific asset, do you consider the relationship between the asset and your existing portfolio?

$\square$ Always consider $\square$ Often consider $\square$ Sometime consider $\square$ Never consider

3. When you evaluate the performance of your portfolio, what is your benchmark?
The initial investment
Riskfree asset
Market portfolio
Other.

4. Investment always entails risks, and high risk is rewarded by high return. Please indicate your risk tolerance by 1 to 5 , where 1 denotes low risk tolerance and 5 denotes high risk tolerance.

5. Which project you will choose among following investment opportunities:

\begin{tabular}{|c|c|c|c|}
\hline & Risk & Expected Return & Volatility of Rate of return \\
\hline$\square$ & Very low & $7.5 \%$ & $5 \% \sim 9 \%$ \\
\hline$\square$ & Low & $9.0 \%$ & $3 \% \sim 12 \%$ \\
\hline$\square$ & Middle & $10.5 \%$ & $0 \% \sim 21 \%$ \\
\hline$\square$ & High & 12.5 & $-3 \% \sim 25 \%$ \\
\hline$\square$ & Very High & $13.5 \%$ & $-9 \% \sim 32 \%$ \\
\hline
\end{tabular}

